\title{
International Knowledge Transfers through Expatriates
}

\author{
Kimmo Riusala - Vesa Suutari
}

\begin{abstract}
Executive Summary
International knowledge transfer processes and related internal stickiness factors have recently been targets of increasing research interest. However, the role of expatriate managers in these international knowledge transfers is not well understood. The objectives of the present study were (1) to analyze what kind of knowledge is transferred within MNCs and what is the role of expatriates in these transfer processes and (2) develop a theoretical framework on internal stickiness factors faced by the expatriates involved in the knowledge transfer processes on the basis of the literature, and test it empirically. The findings indicate that the role of expatriate managers was very central in the transfer processes. Furthermore, support was received for the theoretical framework of internal stickiness factors. (C) 2004 Wiley Periodicals, Inc.
\end{abstract}

\section{INTRODUCTION}

ue to the increasing global integration of business activities, the requirements for learning effective knowledge transfer methods and processes have become even more important than in the past. Behind this change is the globalization of the industry, which puts enormous pressure on companies to adopt global strategies (Morrison, 2000). According to Brake (1999), there are four main organizational principles in the management of organizations with global strategies. First, there is an aim at a high level of integration (i.e., the organization acts as a coordinated network). Second, resources must be able to flow through the organization. Third, there is a drive toward standardization and the reduction of unnecessary duplication. Fourth, the local responsiveness is balanced with global responsibility in order to produce the best results for the total organization. All in all, such aims at standardization, homogenization, concentration, and coordi-

\footnotetext{
Kimmo Riusala works as a researcher at the Levon Institute at the University of Vaasa. His research interest lies in expatriation and international knowledge transfers. E-mail: kimmo.riusala@uwasa.fi. Vesa Suutari is a professor of international management and head of the Department of Management and Organization at the University of Vaasa, Finland. He has specialized on cross-cultural management and international HRM. E-mail: vesa.suutari@uwasa.fi.
}

Thunderbird International Business Review, Vol. 46(6) 743-770 • November-December 2004

(C) 2004 Wiley Periodicals, Inc. • Published online in Wiley InterScience (www.interscience.wiley.com).

DOI: $10.1002 /$ tie. 20034 
nation on a worldwide basis (Svensson, 2001) require effective management of knowledge across borders.

According to Black and Ulrich (1999), the first critical capability that enables firms to integrate global activities appropriately, and also to separate and adapt local activities effectively, is being able to deter-

Issues that belong to the core of a business generally relate to principles that give the firm its identity and issues that are important to customers. mine what belongs to the core of the organization and what does not. Issues that belong to the core of a business generally relate to principles that give the firm its identity and issues that are important to customers. This core should be integrated and standardized throughout worldwide operations. Thus, the transfer of related knowledge and strategic (best) practices becomes the central prerequisite of success (Furu, 2000; Szulanski, 1996).

In line with this, the recent knowledge-based view of the firm focuses on knowledge as the most strategically significant resource of the firm and emphasizes the capacity of the firm to integrate and transfer knowledge (Conner \& Prahalad, 1996; Doz, Santos, \& Williamson, 2001; Grant, 1996b; Mowery, Oxley, \& Silverman, 1996; Spender, 1996). According to the resource-based view, a firm performs well over time because it develops a distinctive strategic competence that allows it to overperform its competitors (Dunphy, Turner, \& Crawford, 1997). For example, Prahalad and Hamel (1994) discuss the core competencies, which are deeply rooted abilities developed and sustained within the organization. If organizational learning is related to the resource-based strategic paradigm, the learning organization will be one where the organization is developing the core competencies that will give it a competitive advantage (Dunphy et al., 1997). Due to the globalization needs, such core competencies have to be effectively transferred across units and borders. It has been even argued that the cross-unit transfer of business practices that reflect the core competencies and superior knowledge is a main determinant of the competitive advantage within multinational companies (MNCs; Conn \& Yip, 1997; Furu, 2000; Kostova, 1999). In the same vein, the major challenges identified when the globalization challenge was looked at from the HR point of view were (1) easily getting the right skills to where they are needed, (2) spreading up-todate knowledge and practices throughout the organization regardless of where they originate, and (3) identifying and developing talent on a global basis (Roberts, Kossek, \& Ozeki, 1998).

Due to the critical role of international knowledge transfers within companies, there has been increasing interest in understanding the stickiness factors that would explain the difficulties related to such 
transfers. This is also related to the fact that for a long time already it has been recognized that such internal transfer is not very successful (see, e.g., Ghoshal \& Bartlett, 1988; Kedia \& Bhagat, 1988; Zander \& Kogut, 1995). This difficulty of transferring knowledge within the organization has often been referred to as internal stickiness (Szulanski, 1996; Teece, 1977; von Hippel, 1994). In light of this background, there have been aims to form theoretical frameworks, though still with fairly little empirical research evidence, on the internal stickiness factors related to internal knowledge transfers (Foss \& Pedersen, 2002; Gupta \& Govindarajan, 2000; Kostova, 1999; Szulanski, 1996).

There are different ways to transfer knowledge across borders. The use of international assignments has become an integral part of MNCs' business strategies. Expatriates act as a link between headquarters (HQ) and foreign subsidiaries, and a great amount of information moves through their hands. The research tradition on expatriation has focused on areas such as selection, adjustment, training, and, more recently, on repatriation and career issues. In line with the increasing attention being paid to knowledge management and core competency issues, there has recently been increasing interest in learning and developmental points of view concerning international assignments (e.g., Antal, 2000; Caligiuri \& DiSanto, 2001; McCall \& Hollenbeck, 2002; Shim \& Paprock, 2002). The first track of research has focused more on the developmental character of international assignments from the individual point of view. This discussion is part of the growing literature on global leader development (for reviews, see Suutari, 2002). The other smaller but increasing research track has started to focus on expatriation as a method for knowledge transfer within MNCs, though empirical work is very scarce.

Because there has not been very much research on the role of expatriates in international knowledge transfer processes, there may be a considerable scope for the development of research based on the notion of expatriates as a means of knowledge transfer (Bonache \& Brewster, 2000; Downes \& Thomas, 2000; Kochan, Batt, \& Dyer, 1992; Oddou \& Osland 2003; Welch, 1994). When this is connected to the earlier discussion on the stickiness factors concerning such knowledge transfers, it appears that this track of research could be further extended by applying such a framework to knowledge transfers through expatriates. In the literature, no earlier work in this area was found, and thus this is the area in which the major contribution of the study exists. In the light of this background, the objectives of the present study are (1) to analyze what kind of knowledge is transferred within
Expatriates act as a link between headquarters $(H Q)$ and foreign subsidiaries, and a great amount of information moves through their hands. 
MNCs and what is the role of expatriates in these transfer processes and (2) to develop a theoretical framework on internal stickiness factors faced by the expatriates involved in the knowledge transfer processes on the basis of the literature, and test it empirically.

With regard to knowledge, the issue of transferability is important, not only between firms, but, even more critically, within the firm...
The theoretical framework building starts from a discussion of the need for international knowledge transfers and continues to the analysis of the internal stickiness to such transfers. After this, the research tradition on expatriates is briefly covered, and the role of expatriates on international knowledge transfers is discussed. As an outcome, a framework concerning the stickiness factors to international knowledge transfer through expatriates is formed. After that, the research methods of the study and the results concerning the expatriates' experiences of the transfer processes are presented. Finally, the conclusion to the theory and practice are drawn.

\section{INTERNATIONAL KNOWLEDGE TRANSFERS AND THE RELATED STICKINESS FACTORS}

The resource-based view of the firm recognizes the transferability of a firm's resources and capabilities as a critical determinant of their competitive advantage (Barney, 1986). With regard to knowledge, the issue of transferability is important, not only between firms, but, even more critically, within the firm (Grant, 1996a). According to Szulanski (1996), the identification and transfer of best practices emerged as one of the most important and widespread practical management issues of the latter half of the 1990s. Especially for an MNC, cross-unit transfer of business practices (i.e., intrafirm or internal transfer) that reflect their core competencies and superior knowledge is a main determinant of their competitive advantage (Furu, 2000; Kostova, 1999). In line with that, Conn and Yip (1997) report that effective international transfer of critical capabilities constitutes the single most important determinant of foreign venture success.

Although scholars have long recognized the strategic importance of internal transfers within MNCs and they are hindered less by confidentiality and legal obstacles than external transfers, there has been substantial evidence that these transfers are not always smooth and successful (e.g., Ghoshal \& Bartlett, 1988; Kedia \& Bhagat, 1988; Lord \& Ranft, 2000; Zander \& Kogut, 1995). This difficulty of transferring knowledge within the organization has often been referred to as internal stickiness (Szulanski, 1996; Teece, 1977; von Hippel, 1994) and can be caused by various factors. There are at least 
four sets of factors likely to influence the difficulty of internal knowledge transfer, and they are linked with the characteristics (1) of the knowledge transferred, $(2)$ of the context in which the transfer takes place, (3) of the source, and (4) of the recipient. The two latter ones are often discussed under the heading of relationship context (Kostova, 1999; Szulanski, 1996).

One central characteristic of knowledge with respect to its transferability is the commonly accepted premise that there are two types of knowledge: tacit and explicit (e.g., Nelson \& Winter, 1982; Polanyi, 1962; Tsoukas, 1996). Tacit knowledge cannot be codified and it is revealed through its application. It has also been called "knowledge of experience," because it is acquired through practical experience and observation rather than formal learning (Grotenhuis \& Weggeman, 2002; Lam, 1997). Without some form of shared experience, it is extremely difficult for people to share each other's thinking processes (Nonaka, 1994). Explicit knowledge refers to knowledge that is transmittable in formal systematic language (e.g., blueprints, manuals, and documents). This ease of communication is its fundamental property.

Kogut and Zander (1993) presented three constructs that measure these different attributes of knowledge (tacit vs. explicit) quite well: codifiability, teachability, and complexity (see also Zander \& Kogut, 1995). Codifiability measures the extent to which the knowledge can be articulated in documents. Teachability measures the ease by which knowledge can be taught to new workers. Complexity is not that easy to measure, but basically it is the number of critical and interacting elements in the knowledge transferred. In the same vein, Lillrank (1995) emphasizes that with clear-cut application, little abstraction is required, as it can be applied in most types of organizations. Issues with a high human component require careful "packaging" before being transferred. Transfer of tacit knowledge between people is slow, costly, and uncertain (Grant, 1996a; Kogut \& Zander, 1992). Kogut and Zander (1993) stated that the more tacit the technology, the more likely it will be transferred within the firm.

In her theoretical framework of the transnational transfer of organizational practices within MNCs, Kostova (1999) emphasizes that process of transfer does not occur in a social vacuum, but it is contextually embedded. She distinguishes three types of context: social, organizational, and relational. With regard to social context, research has shown that there will be country-level effects on the success of transfer, with some countries providing more favorable environments 
for transfer of certain practices and others presenting a number of difficulties and challenges (e.g., Adler, 1995; Hofstede, 1980; Trompenaars, 1993). Kostova (1999) uses institutional theory (see, e.g., Scott, 1995) to conceptualize country-level effects. According to institutional theory regulatory (e.g., laws and rules), cognitive (e.g., frames of thought and schemas), and normative (e.g., values and

Transfer failures are possible, even when both the social and organizational contexts are favorable. norms) components of the institutional environments form a socalled country institutional profile, which can be used to compare the institutional characteristics of different national environments.

In addition to their social embeddedness, transfers are also organizationally embedded, since they occur in a corporate context that can be either favorable or unfavorable regarding a particular practice transferred. Based on earlier studies (e.g., Chatman \& Jehn, 1994; Kedia \& Bhagat, 1988; Rogers, 1980), Kostova (1999) suggests that organizational culture can have two types of effects on the success of practice transfer: general and practice-specific. General effect refers to a cultural orientation an organizational unit has to learning, innovation, and change. Szulanski (1996) uses the terms barren and fertile organizational context, whereas practice-specific effect suggests that the success of transfer will be affected by the compatibility between the values implied by the particular practice and the values underlying the culture of an organizational unit.

Transfer failures are possible, even when both the social and organizational contexts are favorable. A potential reason for failure in such a case could reside in the relationships that exist between the parties involved in the transfer, namely, the source and the recipient. Transfer of knowledge, especially when the knowledge transferred has tacit components, may require numerous individual exchanges (Berthoin, Lenhardt, \& Rosenbrock, 2001; Nonaka, 1994; Szulanski, 1996). The success of such transfer depends, to some extent, on the ease of communication and on the overall relationship between the two parties involved in the transfer process. According to results of Szulanski's (1996) study, arduous (i.e., laborious and distant) relationship between the source and the recipient was one of the most important origins of internal stickiness. One possible explanation for this can simply be lack of relationship - that is, there is not a strong enough personal tie between the source and the recipient of knowledge (O’Dell \& Grayson, 1998).

According to Kostova (1999), there are two types of relationships: attitudinal and power/dependence. Attitudinal relationships reflect a recipient's commitment to, identity with, and trust in the parent 
company. A recipient's perceptions of being dependent on the parent company may provide an alternative source of motivation to comply with the requests for practice transfer and engage actively in this process. Recipients might also be unable to exploit outside sources of knowledge. In other words, they may lack absorptive capacity, which is defined as the ability of the organization to acquire, assimilate, and exploit outside knowledge (Cohen \& Levinthal, 1990; Lam, 1997; Lane \& Lubatkin, 1998; Lane, Salk, \& Lyles, 2001; Mowery et al., 1996). It is largely a function of their pre-existing stock of knowledge-that is, a recipient's ability to add new knowledge to existing knowledge (Dierickx \& Cool, 1989; Grant, 1996a).

All in all, the theoretical stickiness factors could be identified from the literature, though the limitation of these frameworks is the fact that they have not had much empirical validation. On the other hand, this is the area in which the present study can contribute to the generallevel international knowledge transfer theories.

There are different methods to transfer knowledge to foreign affiliates within MNCs. In the present article, the focus is on the role of expatriates in the transfers and, thus, the focus is next turned to the literature on expatriation.

\section{EXPATRIATION AND INTERNATIONAL KNOWLEDGE TRANSFER PROCESSES}

One key area in the field of international human resource management concerns expatriation: cross-border assignments that last a significant period of time (see, e.g., Dowling, Welch, \& Schuler, 1999). Expatriates can be used for a number of different reasons: for specific staffing needs (a vacancy exists in a foreign unit), for management development purposes (development of an internationallyexperienced management team), and for organization development purposes (control and coordination, knowledge transfer, and instilling corporate culture) (see, e.g., Edström \& Galbraith, 1977; Ondrack, 1985; Welch, 1998).

The focus of the expatriation research has traditionally been on predeparture selection and training, and on adjustment and management of expatriates while they are abroad. More recently, the research on repatriation and career impacts of international assignments has increased (see, e.g., Stahl, Miller, \& Tung, 2002; Suutari \& Brewster,
There are different methods to transfer knowledge to foreign affiliates within MNCS. 
2003). At the same time, the importance of the developmental/ knowledge perspective has been raised in the literature, both from the perspective of the individual's learning and development and the perspective of development of knowledge base in the foreign affiliates through the use of international staff transitions.

expatriates are among the basic mechanisms to transfer knowledge.
In the first line of research, the focus is on a learning process that has been found to take place during the international assignments. The international assignment is seen as the major tool for developing global leaders (Black, Morrison, \& Gregersen, 1999; Carpenter, Sanders, Gregersen, 2000; Gregersen, Morrison, \& Black, 1998; Oddou, Mendenhall, \& Ritchie, 2000; Roberts et al., 1998; Seibert, Hall, \& Kram, 1995). Thus, the emphasis of this track of research is increasingly on identifying what kind of learning takes place during the international assignments and on what kind of connection between international assignments and careers after the assignment there is or there could be when developing a global management cadre (see, e.g., Antal, 2000; Caligiuri \& Di Santo, 2001; Gregersen \& Black, 1996; Kamoche, 1997; Riusala \& Suutari, 2000; Selmer, 1999; Shim \& Paprock, 2002; Stahl et al., 2002; Stroh, Gregersen, \& Black, 1998; Suutari \& Brewster, 2003).

The second and quite new research approach, more relevant to the present study, focuses more directly on the knowledge transfers to foreign affiliates through the expatriates (e.g., Bonache \& Brewster, 2000; Downes \& Thomas, 2000; Inkpen, 1998). When an MNC decides to transfer knowledge, particularly tacit knowledge, between different units, it must often assign employees to the foreign operations. In other words, expatriates are among the basic mechanisms to transfer knowledge. For example, Downes and Thomas (2000) state that expatriation is a tool by which organizations can gather and maintain a resident base of knowledge about the complexities of international operations. However, the expatriate literature has not covered this issue extensively, and there may be considerable scope for the development of research based on the notion of expatriates as a means of knowledge transfer (Bonache \& Brewster, 2000; Downes \& Thomas, 2000; Kochan et al., 1992; Oddou \& Osland, 2003; Welch, 1994).

When we combine the theoretical frameworks on international knowledge transfers and apply those to the expatriation, a framework for the present study can be formed (see Figure 1). In the middle, there are knowledge transfers that have taken place across borders. From the point of view of expatriation theories, the role of the expa- 
Figure 1. Theoretical Framework of the Study

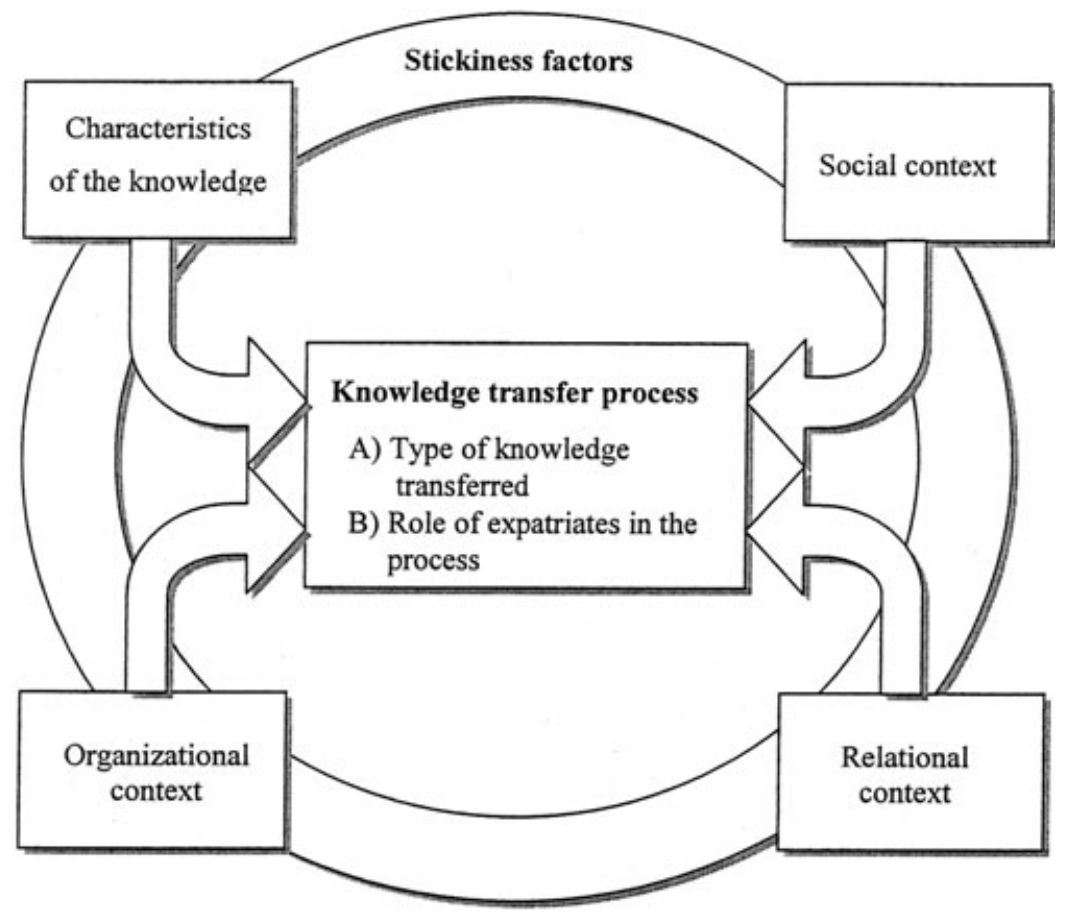

triate in these transfer processes is the key issue to analyze. With regard to the knowledge transfer processes, the framework specifies the internal stickiness factors expected to influence the transfer processes (i.e., type of knowledge, social context, organizational context, and relationship context).

\section{CONTEXT OF THE STUDY}

Poland was perceived to be an excellent context for studying knowledge transfer processes within MNCs, since during the transition period that has followed the collapse of communism in 1989, the development needs have been extensive. The Poland of today stands out as one of the most successful transitional economies in Central and Eastern Europe (CEE). Especially during the second half of the 1990s, Poland was the fastest growing economy in all of Europe, with annual real GDP growth of 5-7\%. Poland was also the first transitional economy in CEE to regain the level of output of 1989, doing so in 1996 . The recovery was initially driven by consumption, then 
by investment and later on by exports (Poland Country Monitor, 2004; Tiusanen, 2004).

At the turn of the century, the Polish economic miracle started to lose steam. A combination of a tighter monetary policy and the adjustments forced on the economy by the 1998 Russian ruble crisis At the turn of the led to a progressive slowing in the pace of GDP growth. GDP growth century, the Pol- decelerated from 4\% in 2000 to $1 \%$ in 2001 (OECD Economic Outish economic look, 2003; Tiusanen, 2004). Also, consumer spending slowed miracle started sharply as unemployment rose to $20 \%$ in 2002 . In contrast to the to lose steam. vibrant expansion of private sector, which is now responsible for $70 \%$ of the country's economic activity, the large agricultural component remains handicapped by severe structural problems (The Country Profile: Poland, 2002; Tiusanen, 2004).

However, the Polish economy has not entered a period of severe crisis. In the beginning of 2004, it seemed that the Polish economy was in the midst of a solid broad-based recovery. GDP growth in 2003 was approximately $3.6 \%$ and it is expected to accelerate to $4.6 \%$ in 2004 (Poland Country Monitor, 2004). Annual growth rates in 2005-2007 are expected to remain in the $4.0-5.0 \%$ range. Also, inflation has decelerated dramatically, from $14.9 \%$ in 1997 to $0.8 \%$ in 2003 . The most serious risk to Poland's outlook in the short-to-medium term is the difficult situation in public finances. The total public debt after the 2004 budget will be above $55 \%$ of GDP and the zloty has fallen to its lowest-ever level against the euro (Poland Country Monitor, 2004). Also, the unemployment rate is still very high-18\% in December 2003. An average gross wage in the enterprise sector amounted to 565 euros in 2003 (IBS World Newsletter, 2004).

After the collapse of communism, considerable changes have naturally happened in the Polish business environment. Western investors and companies recognized the market potentials this largest of the CEE countries, with nearly 40 million inhabitants, could offer. More than 50 billion euros in foreign direct investment have poured into Poland since the onset of political and economic reform (Hunter, Shapiro, \& Ryan, 2003). European Union membership in May 2004 is an important milestone in the country's transition process. On the other hand, the influence of the previous command economy can still be seen, for example, in the leadership behavior of managers and in the high level of bureaucracy in the country's administrative structure (see, e.g., Cave 2003; Suutari \& Riusala, 2000). Differences have been reported to be obvious between different types of companies and, for example, between generations of people (Lang \& Steger, 
2002; Lang \& Wald, 1998; Shama, 1993; Veiga et al., 1995; Weinstein \& Obloj, 2002).

\section{METHOD}

The present study can be classified as a qualitative study in which the data were gathered by doing semistructured telephone interviews among the Finnish expatriates operating in Poland. In total, 24 expatriate managers were interviewed. The major benefit of this method was that the sample of the study could be kept relatively large though the study was qualitative and the interviewees located abroad. This increased the external validity of the findings. Before making the final decision about the method, several pilot telephone interviews were carried out in order to test the functionality of telephone interviews as a data collection method. The other aim of the pilots was to make sure that the respondents were able to understand the questions and see the semistructured interview format as clear and relevant. The experiences from these pilot interviews were very positive and thus no changes were made to the research methods.

The list of Finnish companies with production affiliates, and their contact persons, was received from the Finnish Trade Guild in Poland. Expatriates chosen for the interviews all occupied managerial positions in their host organization and had at least one year's experience working in Poland. The average age of respondents was 42.8 , and all except one were males. Most typically, the respondents operated in the industry sector $(\mathrm{n}=9)$, sales and commercial sector $(\mathrm{n}=6)$, or banking/insurance sector $(\mathrm{n}=5)$. The managers most typically were responsible for Polish operations as CEOs $(\mathrm{n}=15)$, area/country managers $(n=3)$, or industry sector managers $(n=2)$. The rest of the respondents operated as function-level managers. Typically, the companies had operated in Poland over the long term; seven companies had experience of over ten years and ten companies had experience of over five years. The average length of their experience as an expatriate in Poland was 3.8 years at the time of the interview. The group could also be divided into two subgroups of equal size on the basis of their experience: long-term expatriates (mean score 5.8 years) and less experienced ones (mean score 1.9 years).

The interviews were started with the individual and company background details. The first key theme in the interviews was to analyze the types of knowledge transferred across borders (from home country to host country and vice versa) and the role of the expatriate in

The average age of respondents was 42.8 , and all except one were males. 
such transfers. Next, the focus was turned to stickiness factors to the international knowledge transfers that had taken place within the companies. This part of the interview was structured around the stickiness factors specified in the theory section-that is, it was discussed whether the type of knowledge, social context, organizational context, and relationship context were perceived to be stickiness factors in

...previous research and theories were used as a frame of reference, which increases the internal validity of the study. these transfer processes within the companies operating in Poland.

All interviews were recorded and then transcribed. As an outcome, a very extensive qualitative database was achieved. In total, approximately 250 pages of word-by-word transcripts of the interviews were available for analysis. The analysis was started by collecting the comments from 24 interviews, theme by theme. After that, the material was content-analyzed in order to identify common themes appearing from the data. After the identification of the key themes, the data was classified under these themes. In the Results section, these key themes are presented and, at the same time, direct quotations from the interviews are given (in italics) in order to describe the type of evidence behind the conclusions.

The quality of the research project is usually evaluated through concepts of validity and reliability. In the present study, the validity and reliability were improved through the following measures. Construct validity was enhanced through researcher triangulation (e.g., Eisenhardt, 1989; Stake, 1995; Yin, 1989)—-two researchers made separate analysis of the raw data in order to minimize the risk of incorrect interpretations and to increase the likelihood of meaningful findings. In addition, previous research and theories were used as a frame of reference, which increases the internal validity of the study. With regard to external validity, the present study evaluates in-depth evidence on the basis of analytical generalizations. In analytical generalization, a particular set of results is aimed to associate to a broader theory, and thus the sample size is not such a relevant issue (Gummesson, 1991; Remenyi et al., 1998; Yin, 1989). In analytical generalization, the replication facilitates the making of more grounded conclusions. In the present study, the number of interviews was limited to 24 , because at that point it became evident that similar themes emerged repeatedly and the number of new insights became very scarce. Thus, it was considered that the saturation point of this qualitative data collection had been reached.

Research reliability refers to whether the evidence and the measures used are consistent and stable (Miles \& Huberman 1994; Remenyi et al., 1998). A reliable study can be repeated (i.e., another researcher 
should be able to do the study again and get the same results by using the same research procedures). In the present study, the systematic processing of the empirical data (transcripts of the interviews) helps others to follow the different stages of the research process and understand the interpretations researchers have made. Thus, the reliability of the research design was increased by maintaining the chain of evidence and creating a retrievable database (e.g., Remenyi et al., 1998; Yin, 1989).

There are also several key limitations in the study. First, all the expatriates are Finnish, though the companies represented different national origins. Second, all the foreign affiliates were located in Poland. Third, only expatriates' points of view were analyzed; the perspectives of local employees of these transfer processes were excluded from the present study. These issues should be taken into account when making generalizations on the basis of these research findings.

\section{RESULTS}

The results are presented in two major sections in line with the objectives of the study. First, the findings on the type of knowledge transfers and the role of the expatriate in such transfers are reported. Second, the stickiness factors to such knowledge transfers are analyzed.

\section{The Role of the Expatriate in the Knowledge Transfers}

The analysis of the research findings was started from the types of key knowledge transfers. As can be seen in Table 1, the expatriates identified seven most typical key knowledge transfers among the companies in Poland.

The role of the expatriate in these transfer processes was approached from three perspectives: (1) how involved the expatriates had been in key knowledge transfer processes; (2) how autonomous the expatriate manager was on deciding what knowledge was transferred (and

\begin{tabular}{lrlll}
\hline Table 1. Type of Key Knowledge & Transfers to Foreign Affiliates & \\
\hline Management knowledge & 15 & Product/service knowledge & 8 \\
Cultural knowledge & 11 & HRM knowledge & 7 \\
Sales and marketing knowledge & 10 & Accounting/finance knowledge & 6 \\
Technical and production knowledge & 9 & & \\
\hline
\end{tabular}


how); and (3) whether such transfer role had been among the key reasons for sending the expatriate abroad. The respondents reported that their role as expatriate managers involved a lot of general manager responsibilities, which increased their role in the transfer processes. For example, one expatriate described, "My role is to be a sort of 'bridge builder.' In addition to taking care of the know-how transfers

The respondents reported that their role as expatriate managers involved a lot of general manager responsibilities... from Scandinavia to Poland, my responsibilities include transmitting the contextual and cultural knowledge back to Scandinavia so that they would understand the requirements and circumstances over here." The other one stated, "My role is pretty much the transfer of the organizational culture as a whole, but it includes also daily knowledge transfer concerning business philosophy. . . we have frequent discussions concerning daily routines related to either economic management or sales and marketing." Thus, the expatriate managers pointed out that they were, through their managerial roles, connected with the key knowledge transfers that took place.

Second, the expatriate managers reported that they had a high level of autonomy concerning the knowledge transfer decisions within the strategic frames that are decided on the concern level. For example, it was stated, "I have total autonomy. Of course this is within the agreed strategy frames, but within those frames I can manage everything freely" and "There is no clear specification of how things should be carried out, but of course there are some budget frames. Then it is just that we try to transfer thoughts that we have in Scandinavia to Poland. There are no clear guidelines about that, but in a certain way it transmits through the expatriates here. . expatriates try to bring the same philosophy here, but there are no written guidelines on how." In many cases, it was pointed out that, concerning the reporting and related systems, the situation was different since those had to be similar across affiliates. One of the expatriates described this: "I would say that the autonomy exists mainly on organizational issues, training and so on. And when you in turn think about the reporting issues, those are pretty much the same worldwide." All in all, these circumstances leave the expatriate manager a high level of autonomy to decide what needs to be developed locally and what kind of knowledge transfers are involved.

With regard to the centrality of knowledge transfer issues among the original reasons for the use of the expatriate, the experiences differed. The first group of expatriates $(\mathrm{n}=11)$ stated that the knowledge transfer issue was among the conscious central concerns when the decision to send an expatriate to Poland was made. Such expatriates commented, for example, "This is that kind of country where there was 
pretty much emphasis on that (knowledge transfers)" and "Yes, it was in a central role since actually the Transfer Knowledge projects exist in every subarea and in particular in this company, which we started." The rest of the expatriates felt that knowledge transfer issues were not among the key considerations. One of these expatriates argued, " $I$ think that knowledge transfer issues are not in a very conscious role in these issues. Thus, quite often the knowledge transfers are not well taken care of. As an outcome, and in particular if the business is left for locals to handle, it starts to live its own life and soon you don't recognize it as a part of the same concern. These kinds of mistakes have happened fairly often. Then after a few years one has been forced to 'draw back' and those disciplinary actions are tough actions." Behind the descriptions of many such expatriates who did not feel that knowledge transfers had a central role in the decisions, it still appeared that actually they were sent to Poland due to the certain special knowledge/competencies that they had. Thus, it looked as if such a knowledge transfer role did exist, but the expatriates and companies were not used to thinking in knowledge transfer terms about the issue.

\section{INTERNAL STICKINESS FACTORS TO KNOWLEDGE TRANS- FERS}

Next, the findings regarding the perceived stickiness factors to the international knowledge transfers through expatriates are presented in line with the elements of the stickiness factor model presented earlier-the type of knowledge, social context, organizational context, and relationship context. In the analysis, the focus was on the transfer of key knowledge identified above and in particular, such knowledge transfer in which the expatriate had been most involved.

\section{Type of Knowledge}

The first stickiness factor was the type of the knowledge (i.e., explicit vs. implicit/codifiability, teachability, and complexity). Starting from the nature of the knowledge transferred to affiliates, the results were very uniform. The expatriates, with very few exceptions, felt that the type of knowledge included tacit elements (i.e., the knowledge was such that it could not have been transferred through written material only). There were two ways of seeing this. The first group of managers saw clearly that the knowledge that had been transferred was not such that it could have been coded, for example, into written instructions at all (i.e., it was very tacit in nature). Such managers commented, for example, "The knowledge transfer would not have been possible through paper or e-mails. It requires personal con-
The expatriates, with very few exceptions, felt that the type of knowledge included tacit elements... 
tacts and learning" and "These transfers do not work out in such a way that you send the information and the papers and then afterwards you ask how one has succeeded."

The other group of managers saw that such knowledge transfers should instead be seen from two perspectives: (1) the coded written

the complexity of the knowledge transferred was not typically perceived to be among the key stickiness factors to transfers: version of the knowledge (e.g., instructions), which is often useful, and (2) the necessary role of the expatriate to clarify the meaning of knowledge, to see that it is correctly understood, to give his/her own example of how things should be carried out, and to control that the knowledge is actually taken into practice. In conclusion, the codifiability of the knowledge was perceived to be a relevant stickiness factor necessary to take into account in the transfer processes.

With regard to teachability, the situation was not perceived to be so important a stickiness factor, though five expatriates saw that, in their case, teachability of the knowledge was a challenge. For example, these expatriates commented: "The teaching really takes time. One has to be persevering, systematic and persistent. It is very important always to go through issues, to stress the importance of the issue and not turn a blind eye to . . any alterations." This supports the view that teachability is a relevant factor to consider in the transfer processes, though it did not appear as an equally typical stickiness factor as the codifiability and the related tacit nature of the knowledge.

In a similar vein, the complexity of the knowledge transferred was not typically perceived to be among the key stickiness factors to transfers: only four expatriates concluded that the knowledge had been very complex in nature. For example, one such expatriate stated, "The knowledge is complex. When the knowledge transfer through expatriates relates pretty much to ways of working, in which there are attitudes and feelings involved, the transfers are difficult in both directions." Still more common were comments such as "These basic principles are not so complex, but one has to be able to get the other side to understand the situation and the need." All in all, the type of knowledge was perceived to be a relevant stickiness factor to be considered in international knowledge transfers. Most commonly reported was the low codability and, thus, high tacit nature of the knowledge. In turn, low teachability of complexity of the knowledge did not appear so commonly as a stickiness factor on knowledge transfers through expatriates.

\section{Social Context}

The social context was described as involving certain major stickiness factors in knowledge transfers. In the present study, the most com- 
mon stickiness factors were related to regulatory and normative components of the institutional environment. Such issues that could be labeled under the cognitive component of the institutional environment did not appear in the present study.

With regard to the regulatory environment, the major stickiness factor was considered to be bureaucracy of the public authorities $(\mathrm{n}=20)$. The expatriates stated, "Bureaucracy is one of the biggest problems in this country and public authorities aim to stick spokes in the wheels everywhere. . . The situation concerning these authorities is catastrophic" and "They are masters of bureaucracy over here. During the best months we send 400 reports to public authorities." One of the expatriates described his experiences of how to deal with this challenge successfully in the following manner: "This is a very bureaucratic system with which you can manage when you know it. Local support staff, which speaks the local language and knows which office and secretary you need to discuss with in order to have an appointment with the 'big chief' next day, is necessary. Let's say that a lot of documents and stamps are necessary." Such stickiness factors naturally slow down the transfer processes in which public authorities have a role.

Another feature of the regulatory environment that emerged as an internal stickiness factor was issues related to legislation and taxation $(\mathrm{n}=10)$. One of the respondents described how this influenced knowledge transfer success: "The planning of business operations is bere more difficult, e.g. when here you need to do closing of the books once a month. So the planning of the result or optimization of taxation . . . is much more difficult here and thus the transfer of that part of the knowledge concerning economic administration stops at that, since you cannot do it in the way you have learnt to do it and wish to do it."

The most common stickiness factor with regard to the normative environment was cultural issues such as high power distance and lack of openness in the culture $(n=12)$. Concerning the high power distance, the major outcomes are high authoritative needs and the need to control those below you. One expatriate described the situation in the following manner: "I have discussed with many colleagues here about the situation in organizations . . . in particular, people bere keep back information and they are not open, transparent, it is short of political scheming. Polish are quite difficult to lead in that way. In the end. . . you have to use your decision making power. . . and you must follow-up the instructions you have given to them." However, the same person also stressed that, in the short
With regard to the regulatory environment, the major stickiness factor was considered to be bureaucracy of the public authorities. 
term, authoritativeness works, but in that way the organization does not develop and people do not give their best effort if the system is too authoritative.

Another characteristic of the normative environment was the traditional use of bribes and "gifts" everywhere $(n=9)$. This issue is The clear major- related to the regulatory environment (i.e., relationships with pubity of the lic authorities), but the same issue appeared in the business as well: respondents saw "There is horrible corruption still around... This is one of the problems that the general in Poland. We decided to look for external juridical help and managed organizational context was supportive of change and to resolve the problem." The other one concluded that "most of our customers accept some sort of bribes and thus smaller and mediumsized companies such as we have lost a lot of deals since we did not give any envelopes."

innovation.

In addition, there were few comments $(n=5)$ about the shortages of the local infrastructure, in particular, the poor conditions of rural roads, railways, and telecommunication systems. All in all, the social context was clearly seen to be a relevant stickiness factor to consider in the knowledge transfer processes.

\section{Organizational Context}

Next, the focus was turned to the organizational context in order to analyze whether the suggested organizational context had emerged as a stickiness factor in the knowledge transfer processes. Two types of factors were identified in the theoretical phase: general and practice-specific. The clear majority $(n=19)$ of the respondents saw that the general organizational context was supportive of change and innovation. This quite unexpected picture within a transition economy was partly explained by the two different characteristics of the organizations. First, the organizations often consisted of representatives of the young generation due to the extensive difference between different generations of people. One of the expatriates described this in the following manner: "I would say that this (organizational context) is very inspiring/innovative. Maybe the biggest problems were the persons who represented the older generation-for those an idea about a change is pretty difficult. Mainly the staff is now very young ... in that way the enthusiasm and willingness (to learn and change) is high." The other one concluded, "This young group around their 30 s is very well educated and highly motivated . . . I would say that this has been a very learning type of organizational context." The easiness of making staff changes in this context has given managers a possibility of quite freely replacing people who were not seen to adjust to operate in a manner required. 
Another common characteristic concerning the staff was the high level of education of recruited people. The respondents described, "The starting point has been to recruit people with high (academic) education. This kind of recruitment is built on the idea that then they have good capability to learn new things" and "We looked for such staff as was not so tracked, with not too much experience either during the socialism or the transition period ... all with university level education. The good side is that there are enough such people available. The level of education is surprisingly high, at least on the theoretical side."

There were only five expatriates who felt that the organizational context was not supportive of innovation and change. These respondents described, "They were not ready for changes in the manner people in the Nordic countries have learned to be. Every change has to be sold to them" and "I would describe this (organizational context) as having a high level of resistance to change. It is really difficult to achieve an open and change-supporting climate: people are suspicious . . one really has to look carefully on how you sell these things to the organization. You have to be very clear and explain the backgrounds clearly. In a certain phase, one has to take a sort of authoritative attitude... in a certain phase the discussion has to be ended and the supervisor has to take an active role and one has to control also." The other typical organizational characteristics that were found to be stickiness factors were the authoritative decision-making tradition, lack of open communication, and tight division of work and the related lack of responsibility for taking over issues not described in exact job descriptions. Similar factors already emerged earlier when factors concerning the social context were discussed.

With regard to practice-specific stickiness factors, the expatriates typically felt the absorptive capacity of the organization was not generally a problem: "I would say that capacity to adopt this knowledge has been good. I would even claim that it does not differ from the Nordic context at all. It may even be the other way round, since the willingness to 'Westernize' is so high." Again, the differences between the generations were stressed: "The level of education is involved here, i.e. people bave different education backgrounds and different capacity to learn this knowledge. The younger generation was much more capable of learning than the older one ... the older group simply could not follow."

\section{Relationship Context}

Concerning the relationship contexts, two types of relationships were identified in the theory section: attitudinal (commitment to, identity with, and trust in the parent company) and power/dependence rela-
There were only five expatriates who felt that the organizational context was not supportive of innovation and change. 
tionships. Starting from the commitment of the locals to the company, it appeared the majority of the expatriates $(n=18)$ saw that the locals were fairly or even very highly committed. The expatriates described, "Yes, they are very committed to the company. They are even proud that they can work in a Finnish company" and "I would say that we have succeeded in increasing commitment very well and the people .the majority of are committed from the depth of their hearts." Thus, in most compathe expatriates nies, lack of commitment was not seen to be an internal stickiness facsaw that the locals were mainly committed to the local tor to the development. organization.

However, six expatriates saw that the commitment of employees is low in their companies. One of the expatriates explained this by the importance of monetary rewards, which, according to him, was connected with the low standard of living in history: "The only thing that commits these people is the money. People run after money here and organizational commitment and loyalty disappears in a moment when someone has a higher salary or a better car." It was also pointed out that the situation is more peculiar to Warsaw in particular, since there the cost of living is high.

Concerning identification with the parent company, the majority ( $\mathrm{n}$ $=15$ ) of the expatriates saw that the locals were mainly committed to the local organization. Such respondents commented, for example, "I would say that they identify themselves very strongly with the local unit. The concern is fairly distant to them ... It is so distant a function to them how all this functions and who decides over there, and to whom you should talk." Another commented, "Identification with the concern is very low and it is that kind of issue on which we have to focus much attention. Staff exchanges is one of the means . . In that natural way the identification is born." The rest of the respondents saw that the staff identified themselves with both the local unit and the parent company. Such identification with the parent company increases the successfulness of the knowledge transfers due to shared values and goals. Few respondents pointed out that there were differences within organizational levels on this-for example, "The sales persons and the management (are identified) also with the concern but local employees mainly with the local unit."

With regard to trust in the parent company, the clear majority ( $\mathrm{n}=$ 21 ) of the expatriates perceived that there existed a trust between the parent company and the locals. Thus, the lack of trust was not seen to be among the stickiness factors toward the development. For example, it was stated, "The honesty is very high in all Finnish companies so that if the representatives of the parent company say something, 
or I say, then the locals trust that." One of the respondents saw that there are three factors behind the trust in all the Nordic companies: "First, there have not been any conflicts between the nations in 200 years ... Second, the business in Nordic countries is not corrupted and thus those companies are valued. The third factor is the good environmental image the companies have here." Those few ones with a negative feeling about the trust commented, for example, "I think that it is right that such trust does not exist since the parent company leaves this company if it is not profitable within a few years."

Recipients' perceptions of being dependent on the parent company may provide an alternative source of motivation to comply with the requests for practice transfer and engage actively in this process. With regard to this power/dependence, the majority $(n=17)$ of the expatriates saw that foreign affiliates were fairly highly dependent on the parent company, an issue that increases the motivation and need to transfer knowledge. Such expatriates commented, for example, "On a practical level, when you think about knowledge transfer and knowhow, we are very dependent on the mother company" and "the daughter company is completely dependent on the parent company." Some of the managers saw that the situation is still, to some extent, twofold, saying that "the daily business is fairly autonomous, but the dependence concerns rather economic affairs and business support issues" or that "we are fairly independent, but if we have economic problems the dependence increases."

\section{CONCLUSIONS}

The objectives of the present study were (1) to analyze what kind of knowledge is transferred within MNCs and what is the role of expatriates in these transfer processes and (2) to develop a theoretical framework on internal stickiness factors faced by the expatriates involved in the knowledge transfer processes on the basis of the literature, and test it empirically. The study was classified as a qualitative study in which the data were gathered by doing semistructured telephone interviews among 24 Finnish expatriates operating in Poland.

The results of the study indicated that the key areas of knowledge transfer were management knowledge, cultural knowledge, technical knowledge, sales and marketing knowledge, product knowledge, HRM knowledge, and accounting/finance knowledge. The knowledge transferred from the foreign affiliates to headquarters could be classified into two different groups-knowledge about the local envi- 
The results indicated that the role of the expatriate manager was very central... ronment and knowledge concerning the operations and success of the affiliate itself. The role of the expatriates in these international knowledge transfer processes has been stressed in the literature (Bonache \& Brewster, 2000; Downes \& Thomas, 2000; Inkpen, 1998; Kochan et al., 1992; Oddou \& Osland, 2003; Welch 1994). The present study provided new empirical evidence to support this. First, it was analyzed how involved the expatriates are in such processes and how autonomous they are in deciding what type of knowledge transfer processes take place within MNCs. The results indicated that the role of the expatriate manager was very central - that is, the expatriate managers pointed out that they were highly involved with the key knowledge transfers that took place across the borders. The expatriate managers also reported that they had a high level of autonomy concerning decisions on what to develop locally and what kind of knowledge transfers are necessary within the strategic frames given by the parent company. The majority of expatriates also reported that the knowledge transfer was among the central concerns when the expatriate was originally selected. Also, in many other cases, knowledge transfer issues were involved, though they were not so consciously discussed. Some respondents stressed that transfer issues should have a more central role in the selection process.

All these findings supported the view of the importance of expatriates in international knowledge transfer processes. At the same time, the picture that appeared was such that since the decisions concerning the knowledge transfers and integration were pretty much left to individual expatriates, the MNCs did not have systematic knowledge management processes in an international context. In that way, the level of systematic integration and standardization was not very high yet, though in the literature, it is discussed that in many fields of industry importance of such issues will increase in the future (e.g., Black \& Ulrich, 1999; Brake, 1999; Morrison, 2000; Szulanski, 1996).

The results supported the relevance of the theoretical framework of internal stickiness factors when applied to the knowledge transfer processes through expatriates. This framework was mainly built on the theoretical frameworks by Szulanski (1996) and Kostova (1999), and thus the study provided new empirical evidence on the relevance of these frameworks in the expatriation context. First, the results indicated that the type of knowledge was perceived to be a relevant stickiness factor to be considered in international knowledge transfers. The most common knowledge-related internal stickiness factor appeared to be the low codifiability of the knowledge and thus the 
high tacit nature of the knowledge that was transferred. Such tacit nature of knowledge is among the most discussed internal stickiness factors in the transfer processes in the literature, too (e.g., Bonache \& Brewster, 2000; Grant, 1996a; Kogut \& Zander, 1992; Nonaka, 1994). This, in turn, emphasized the role of expatriates in providing background information and explanations, and the related need for personal interaction and on-the-job observation and teaching on the transfer processes (Grotenhuis \& Weggeman, 2002; Lam, 1997). In turn, low teachability or complexity of the knowledge did not appear so commonly as an internal stickiness factor to the knowledge transfers through expatriates. This might be related to the specific nature of expatriation as a knowledge transfer method; through the personal presence of an expatriate, it is possible to transfer quite a complex type of knowledge without bigger problems.

The social context was typically described to involve certain internal stickiness factors in knowledge transfers. The most common contextrelated internal stickiness factor appeared to be the bureaucracy of public authorities, cultural issues, legislation and taxation; the use of gifts/bribes within the context; and the infrastructure. These issues can be well connected to the existing understanding of the context. For example, the high level of bureaucracy and role formalization, and the related difficulty in relationships with public authorities, is commonly pointed out in the literature (Garrison \& Artemyev, 1994; Hisrich \& Jones, 1992; Smith, Dugan, \& Trompenaars, 1996; Suutari \& Riusala, 2000). Similarly, the existence of the corruption and certain cultural stickiness factors as high power distance and lack of open communication have been widely discussed in literature concerning the former Communist countries (Soulsby \& Clark, 1996; Suutari \& Riusala, 2001). All in all, the social factors were found to be important stickiness factors to consider in international knowledge transfer processes.

With regard to internal stickiness factors related to organizational context, the results indicated that such factors did not have so central a role on the transfer processes, though the relevance of this stickiness factor was still supported. The respondents typically saw that the organizational context was supportive of change and innovation. This quite unexpected picture was explained by the two different characteristics of the local staff-the young age structure and high level of education. The extensive difference between the generations of employees within transition economies has been pointed out in earlier research (Shama, 1993; Suutari \& Riusala, 2001; Veiga et al., 1995). The differences across different types of business operations were also pointed out. 
Concerning the relationship contexts, two types of relationships were analyzed: attitudinal and power/dependence relationships. The commitment of the locals to the company appeared to be typically fairly or even very high. The locals were mainly committed to the local organization though it was also fairly common that the staff were seen to identify themselves with both the local unit and the mother

The findings of the present study also have implications for the companies' knowledge management processes. company. Higher level of identification with the parent company in turn increases the successfulness of the knowledge transfers due to shared values and goals. With regard to the trust with the parent company, the clear majority of the expatriates perceived that a lack of such trust was not a problem. With regard to power/dependence, the majority of the expatriates saw that foreign affiliates were fairly highly dependent on the parent company, an issue that increases the motivation and need to transfer knowledge.

All in all, the analysis of internal stickiness factors supported the relevance of the theoretical framework. Thus, the original framework does not require revision, though the general knowledge transfer theories were now applied in the expatriate context. The clear limitations of the study were that only the views of the expatriates were heard. Thus, in future studies, the local point of view could have a more central role. In addition, all the expatriates were Finns and they operated in Poland. Thus, the research could be expanded to other types of contexts in order to discover the extent to which the findings differ across context. On the other hand, the contextual model can take this into account-that is, the theoretical elements may remain the same though their level of importance may vary across contexts. The other question is whether the theoretical framework already captures all the major theoretical stickiness elements. At least in the present study, the framework received support and no totally new elements emerged during the interviews.

The findings of the present study also have implications for the companies' knowledge management processes. First, the central role of expatriate managers in the transfer processes emphasizes the importance of selecting the candidates who possess adequate competencies (e.g., education, experience) needed to manage these challenging cross-border knowledge transfers. Furthermore, training should be provided for expatriates who will be responsible for conducting these international knowledge transfers. The results also indicate that the transfer of knowledge was not very systematically managed within the companies. If the arguments about the increasing need for international integration and knowledge transfers across borders in the future are taken seriously, the companies should focus more system- 
atically on identifying their core knowledge and managing the transfer of such knowledge across units. Such decisions should not be fully left to individual managers to decide and handle.

In addition, the theoretical framework introduced in the present study can help companies understand the different elements that should be taken into account when international knowledge transfers are planned and executed. This is very important, because failures or setbacks in international knowledge transfer processes are extremely costly and often caused by the internal stickiness factors described in this study.

\section{REFERENCES}

Adler, N. J. (1995). International dimensions of organizational behaviour. Boston: PWS-Kent. Antal, A. B. (2000). Types of knowledge gained by expatriate managers. Journal of General Management, 26(2), 32-51.

Barney, J. B. (1986). Strategic factor markets: Expectations, luck, and business strategy. Management Science, 32, 1231-1241.

Berthoin, A., Lenhardt, U., \& Rosenbrock, R. (2001). Barriers to organizational learning. In M. Dierkes, A. Berthoin, J. Child, \& I. Nonaka (Eds.), Handbook of organizational learning (pp. 865-885). Oxford: Oxford University Press.

Black, J. S., Morrison, A. J., \& Gregersen, H. B. (1999). Global explorers: The next generation of leaders. London: Routledge.

Black, J. S., \& Ulrich, D. (1999). The new frontier of global HR. In P. Joynt \& B. Morton (Eds.), The global HR manager (pp. 12-38). London: Institute of Personnel and Development.

Bonache, J., \& Brewster, C. (2000). Knowledge transfer and the management of expatriation. Thunderbird International Business Review, 43, 145-168.

Brake, T. (1999). The HR manager as global business partner. In P. Joynt \& B. Morton (Eds.), The global HR manager (pp. 59-87). London: Institute of Personnel and Development.

Caligiuri, P., \& Di Santo, V. (2001). Global competence: What is it, and can it be developed through international assignments? Human Resource Planning, 24(3), 27-35.

Carpenter, M. A., Sanders, W. G., \& Gregersen, H. B. (2000). International assignment experience at the top can make a bottom-line difference. Human Resource Management, 39, 277-285.

Cave, A. (2003). Emerging markets: Topping the poles. Director, 57(3), 55-57.

Chatman, J., \& Jehn, K. (1994). Assessing the relationship between industry characteristics and organizational culture: How different can you be? Academy of Management Journal, 37, $522-553$.

Cohen, W. M., \& Levinthal, D. (1990). Absorptive capacity: A new perspective on learning and innovation. Administrative Science Quarterly, 35, 128-152.

Conn, H. P., \& Yip, G. S. (1997). Global transfer of critical capabilities. Business Horizons, $40(1), 22-31$.

Conner, K., \& Prahalad, C. K. (1996). A resource-based theory of the firm: Knowledge versus opportunism. Organization Science, 7, 477-501.

The country profile: Poland. (2002). London: The Economist Intelligence Unit Limited.

Dierickx, I., \& Cool, K. (1989). Asset stock accumulation and sustainability of competitive advantage. Management Science, 35, 1504-1513.

Dowling, P. J., Welch, D. E., \& Schuler, R. S. (1999). International human resource management-Managing people in a multinational context (3rd ed.). Cincinnati, OH: South-Western College Publishing.

Downes, M., \& Thomas, A. S. (2000). Knowledge transfer through expatriation: The U-curve approach to overseas staffing. Journal of Managerial Issues, 12, 131-149. 
Doz, Y., Santos, J., \& Williamson, P. (2001). From global to metanational: How companies win in the knowledge economy. Cambridge: Harvard Business School Press.

Dunphy, D., Turner, D., \& Crawford, M. (1997). Organisation learning as the creation of corporate competencies. Journal of Management Development, 16, 232-244.

Edström, A., \& Galbraith, J. (1977). Transfer of managers as a coordination and control strategy in multinational organizations. Administrative Science Quarterly, 22, 249-263.

Eisenhardt, K. M. (1989). Building theories from case study research. Academy of Management Review, 14, 532-550.

Foss, N., \& Pedersen, T. (2002). Transferring knowledge in MNCs: The role of sources of subsidiary knowledge and organizational context. Journal of International Management, 8, 1-19.

Furu, P. (2000). Development and transfer of competence in the multinational corporation: Foreign subsidiaries as centers of excellence. Helsinki: Swedish School of Economics and Business Administration.

Garrison, T., \& Artemyev, A. (1994). Managing people in Russia. In T. Garrison \& D. Rees (Eds.), Managing people across Europe (pp. 122-139). Oxford: Butterworth-Heineman.

Ghoshal, S., \& Bartlett, C. A. (1988). Creation, adoption and diffusion of innovations by subsidiaries of multinational corporations. Journal of International Business Studies, 19, 365-388.

Grant, R. M. (1996a, Winter). Toward a knowledge-based theory of the firm. Strategic Management Journal, 17, 109-122.

Grant, R. M. (1996b). Prospering in dynamically-competitive environments: Organizational capability as knowledge integration. Organization Science, 7, 375-387.

Gregersen, H. B., \& Black, J. S. (1996). Multiple commitments upon repatriation: The Japanese experience. Journal of Management, 22, 209-229.

Gregersen, H. B., Morrison, A. J., \& Black, J. S. (1998, Fall). Developing leaders for the global frontier. Sloan Management Review, pp. 21-32.

Grotenhuis, F., \& Weggeman, M. (2002). Knowledge management in international mergers. Knowledge and Process Management, 9(2), 83-89.

Gummesson, E. (1991). Qualitative methods in management research. Newbury Park, CA: Sage. Gupta, A. K., \& Govindarajan, V. (2000). Knowledge flows within multinational corporations. Strategic Management Journal, 21, 473-496.

Hisrich, R. D., \& Jones, J. (1992). U.S./Hungarian joint ventures: An opportunity for entering new markets. Journal of Global Marketing, 5(3), 89-108.

Hofstede, G. (1980). Culture's consequences: International differences in work-related values. Beverly Hills, CA: Sage.

Hunter, R. J., Jr., Shapiro, R. E., \& Ryan, L. V. (2003). Taxes, development, and economic transition: An update on Polish taxation. The International Tax Journal, 29(4), 1-21.

IBS World Newsletter 1/04. (2004). International Business Statistics, Statistics Finland, Helsinki.

Inkpen, A. C. (1998). Learning and knowledge acquisition through international strategic alliances. Academy of Management Executive, 12(4), 69-80.

Kamoche, K. (1997). Knowledge creation and learning in international HRM. The International Journal of Human Resource Management, 8, 213-225.

Kedia, B., \& Bhagat, R. (1988). Cultural constraints on transfer of technology across nations: Implications for research in international and comparative management. Academy of Management Review, 13, 559-571.

Kochan, T., Batt, R., \& Dyer, R. (1992), International human resource studies: A framework for future research. In D. Lewin, O. Mitchell, \& P. Scheller (Eds.), Research frontiers in industrial relations and human resources (pp. 309-337). Madison, WI: Industrial Relations Research Association.

Kogut, B., \& Zander, U. (1992). Knowledge of the firm, combinative capabilities, and the replication of technology. Organization Science, 3, 383-397.

Kogut, B., \& Zander, U. (1993). Knowledge of the firm and the evolutionary theory of the multinational corporation. Journal of International Business Studies, 24, 625-645.

Kostova, T. (1999). Transnational transfer of strategic organizational practices: A contextual perspective. Academy of Management Review, 24, 308-324.

Lam, A. (1997). Embedded firms, embedded knowledge: Problems of collaboration and knowledge transfer in global cooperative ventures. Organization Studies, 18, 973-996. 
Lane, P., \& Lubatkin, M. (1998). Relative absorptive capacity and interorganizational learning. Strategic Management Journal, 19, 461-477.

Lane, P., Salk, J., \& Lyles, M. (2001). Absorptive capacity, learning, and performance in international joint ventures. Strategic Management Journal, 22, 1139-1161.

Lang, R., \& Steger, T. (2002). The odyssey of management knowledge to transforming societies: A critical review of a theoretical alternative. Human Resource Development International, $5,279-294$.

Lillrank, P. (1995). The transfer of management innovations from Japan. Organization Studies, $16,971-986$.

Lord, M. D., \& Ranft, A. L. (2000). Organizational learning about new international markets: Exploring the internal transfer of local market knowledge. Journal of International Business Studies, 31, 573-589.

McCall, M. W., \& Hollenbeck, G. P. (2002). Developing global executives: The lessons of international experience. Boston: Harvard Business School Press.

Miles, M. B., \& Huberman, A. M. (1994). Qualitative data analysis. Thousand Oaks, CA: Sage Publications.

Morrison, A. J. (2000). Developing a global leadership model. Human Resource Management, $39,117-132$.

Mowery, D. C., Oxley, J. E., \& Silverman, B. S. (1996, Winter). Strategic alliances and interfirm knowledge transfer. Strategic Management Journal, 17, 77-99.

Nelson, R., \& Winter, S. (1982). An evolutionary theory of economic change. Cambridge: Belknap Press.

Nonaka, I. (1994). A dynamic theory of organizational knowledge creation. Organization Science, 5(1), 14-37.

Oddou, G., Mendenhall, M. E., \& Ritchie, J. B. (2000). Leveraging travel as a tool for global leadership development. Human Resource Management, 39, 159-172.

Oddou, G., \& Osland, J. (2003). The transfer of repatriate assets: Variables influencing the knowledge transfer. In Proceedings of the 7th Conference on International Human Resource Management "Exploring the Mosaic, Developing the Discipline," University of Limerick, Ireland.

O’Dell, C., \& Grayson, J. C. (1998). If only we knew what we know: Identification and transfer of internal best practices. California Management Review, 40(3), 154-174.

OECD economic outlook. (2003). Volume 2003/1, No. 73, June. Paris: Organisation for Economic Co-operation and Development.

Ondrack, D. (1985). International transfers of managers in North American and European MNCs. Journal of International Business Studies, 16(3), 1-19.

Poland country monitor. (2004). Jan 2004. Boston: Global Insight Inc.

Polanyi, M. (1962). Personal knowledge: Towards a post-critical philosophy. Chicago: Chicago University Press.

Prahalad, C. K., \& Hamel, G. (1994). Competing for the future. Boston: Harvard Business School Press.

Remenyi, D., Williams, A. M., \& Swartz, E. (1998). Doing research in business and management: An introduction to process and method. London: Sage Publications.

Riusala, K., \& Suutari, V. (2000). Expatriation and careers: Perspectives of expatriates and spouses. Career Development International, 5(2), 81-90.

Roberts, K., Kossek, E. E., \& Ozeki, C. (1998). Managing the global workforce: Challenges and strategies. Academy of Management Executive, 12(4), 93-119.

Rogers, E. (1980). Diffusion of innovations. New York: Free Press.

Scott, R. (1995). Institutions and organizations. Thousand Oaks, CA: Sage Publications.

Seibert, K. W., Hall, D. T., \& Kram, K. E. (1995). Strengthening the weak link in strategic executive development: Integrating individual development and global business strategy, Human Resource Management, 34, 549-567.

Selmer, J. (1999). Career issues and international adjustment of business expatriates. Career Development International, 4(2), 77-87.

Shama, A. (1993). Management under fire: The transformation of managers in the Soviet Union and Eastern Europe. Academy of Management Executive, 7(1), 22-35.

Shim, I., \& Paprock, K. E. (2002). A study focusing on American expatriates' learning in host cultures. International Journal of Training and Development, 6(1), 13-24. 
Smith, P. B., Dugan, S., \& Trompenaars, F. (1996). National culture and the values of organisational employees: A dimensional analysis across 43 nations. Journal of Cross-Cultural Psychology, 27, 231-264.

Soulsby, A., \& Clark, E. (1996). The emergence of post-communist management in the Czech Republic. Organisation Studies, 17, 227-247.

Spender, J.-C. (1996, Winter). Making knowledge the basis of a dynamic theory of the firm. Strategic Management Journal, 17, 45-62.

Stahl, G. K., Miller, E. L., \& Tung, R. L. (2002). Toward the boundaryless career: A closer look at the expatriate career concept and the perceived implications of an international assignment. Journal of World Business, 37, 216-227.

Stake, R. E. (1995). The art of case study research. Thousand Oaks, CA: Sage Publications.

Stroh, L. K., Gregersen, H. B., \& Black, J. S. (1998). Closing the gap: Expectations versus reality among expatriates. Journal of World Business, 33, 111-124.

Suutari, V. (2002). Global leader development: An emerging research agenda. Career Development International, 7(4), 218-233.

Suutari, V., \& Brewster, C. (2003). Repatriation: Empirical evidence from a longitudinal study of careers and expectations among Finnish expatriates. International Journal of Human Resource Management, 14, 1132-1151.

Suutari, V., \& Riusala, K. (2000). Operating in "economies in transition"-Adjustment and management issues faced by Finnish expatriate managers. The Finnish Journal of Business Economics, 49(1), 87-107.

Suutari, V., \& Riusala, K. (2001). Leadership styles in Central Eastern Europe: Experiences of Finnish expatriates in the Czech Republic, Hungary and Poland. Scandinavian Journal of Management, 17, 249-280.

Svensson, G. (2001). 'Glocalization' of business activities: A 'glocal strategy' approach. Management Decision, 39, 6-18.

Szulanski, G. (1996, Winter). Exploring internal stickiness: Impediments to the transfer of best practice within the firm. Strategic Management Journal, 17, 27-43.

Teece, D. (1977, June). Technology transfer by multinational corporations: The resource cost of transferring technological know-how. Economic Journal, pp. 242-261.

Tiusanen, T. (2004). Poland, the largest new EU country. Publication 4. Lappeenranta: Lappeenranta University of Technology, Northern Dimension Research Centre.

Trompenaars, F. (1993). Riding the waves of culture. London: The Economist Books.

Tsoukas, H. (1996, Winter). The firm as a distributed knowledge system: A constructionist approach. Strategic Management Journal, 17, 11-25.

Veiga, J. N., Yanouzas, J. N., \& Buchholtz, A. K. (1995, July/August). Emerging cultural values in Russia: What will tomorrow bring? Business Horizons, pp. 20-27.

von Hippel, E. (1994). "Sticky information" and the locus of problem solving: Implications for innovation. Management Science, 40, 429-439.

Weinstein, M., \& Obloj, K. (2002). Strategic and environmental determinants of HRM innovations in post-socialist Poland. International Journal of Human Resource Management, 13, 642-659.

Welch, D. (1994). Determinants of international human resource management approaches and activities: A suggested framework. Journal of Management Studies, 31(2), 139-164.

Welch, D. (1998). The psychological contract and expatriation: A disturbing issue for IHRM? Paper presented at 6th Conference on International Human Resource Management, University of Paderborn.

Yin, R. K. (1989). Case-study research: Design and methods. Thousand Oaks, CA: Sage.

Zander, U., \& Kogut, B. (1995). Knowledge and the speed of the transfer and imitation of organizational capabilities: An empirical test. Organization Science, 6, 76-92. 